DOI 10.4467/25439561KSR.21.011.14422

Magdalena Dyras (D) https://orcid.org/0000-0003-2694-0212

Uniwersytet Jagielloński

Kraków

\title{
PAMIĘĆ „MNIEJSZOŚCIOWA” I POKALECZONA W NAJNOWSZEJ LITERATURZE CHORWACKIEJ (NA PRZYKŁADACH PROZY LUDWIGA BAUERA, IVANY ŠOJAT KUČI I SLOBODANA ŠNAJDERA)
}

\author{
“MINORITY” AND MUTILATED MEMORY AS DEPICTED \\ IN THE LATEST CROATIAN LITERATURE \\ (IN REPRESENTATIVE EXAMPLES OF PROSE BY LUDWIG BAUER, \\ IVANA ŠOJAT KUČI AND SLOBODAN ŠNAJDER)
}

\section{Streszczenie}

W artykule została poruszona problematyka pamięci zbiorowej oraz indywidualnej, na przykładzie traumatycznych doświadczeń mniejszości niemieckiej (tzw. Szwabów) w Jugosławii (w latach 1945-1990). Trwająca kilkadziesiąt lat konfiskata pamięci skutkowała utratą tożsamości, którą po 1990 roku trzeba było na nowo zbudować. Sposobem na jej odzyskanie stały się narracje literackie, motywowane pamięcią pokaleczoną przez system autorytarny. Problematykę tę poruszono między innymi w trzech powieściach, których publikacja spotkała się z ożywioną reakcją badaczy i krytyków literatury. Są to Ludwiga Bauera Kratka kronika porodice Weber, Ivany Šojat Kuči Unterstadt i Slobodana Šnajdera Doba mjedi. Pamięć, zgodnie z ustaleniami teoretycznymi Elżbiety Rybickiej, została ukazana zarówno jako koncept literaturoznawczy, jak również kategoria egzystencjalna. Powieści przywołanych autorów ilustrują, w jaki sposób literatura staje się medium i nośnikiem pamięci. 


\begin{abstract}
The article deals with the issues of collective and individual memory, based on the example of traumatic experiences of German minority (so-called Swabians) in Yugoslavia (1945-1990). Decades-long confiscation of memory resulted in the loss of identity, which had to be rebuilt after 1990. Literary narratives, motivated by mutilated memory resulting from the authoritarian system, became the way to regain it. These issues are discussed, among others, in three novels, the publication of which met with a lively response from researchers and critics of literature. These are Ludwig Bauer's A Brief Chronicle of the Weber Family, Ivana Šojat Kuči's Unterstadt and Slobodan Šnajder's The Age of Brass. Memory, according to theoretical findings of Elżbieta Rybicka, has been presented both as a literary concept and an existential category. The novels by the above-mentioned authors illustrate how literature becomes a medium and a carrier of memory.
\end{abstract}

Słowa kluczowe: współczesna proza chorwacka, pamięć, przemilczenia, tożsamość, medium pamięci

Keywords: contemporary Croatian prose, memory, omissions, identity, memory medium

Doświadczenia i pamięć II wojny światowej, mimo upływu dziesięcioleci, jakie dzielą nas od tych bolesnych wydarzeń historycznych, stanowią nadal inspirację narracji literackich, tożsamościowych, jak również pozostają tematem dyskusji toczących się w ostatnich latach, także w Chorwacji. Jak zauważa historyczka Snježana Koren

„The World War topics have been in the center of bitter debates ever since Croatia gained its independence at the beginning of the 1990s. The roots of these political debates and ideological conflicts need to be traced not only in World War II events, but also in post-1945 and post-1990 interpretations of these events" ${ }^{1}$.

Badaczka zwraca uwagę na fakt powołania przez rząd chorwacki nowej instytucji, a mianowicie Rady do spraw Konsekwencji działań Reżimów Niedemokratycznych (Council for Dealing with the Consequences of Undemocratic Regimes, dnia 2.03.2017), której zadaniem jest podejmowanie oceny i re-interpretacji wydarzeń historycznych sprzed niemal 70 lat, ponieważ nieustannie oddziałują one na bieżące wydarzenia.

${ }^{1}$ S. Koren, Dialogue Document Without Dialogue: Current Debates on World War II in Croatia, „Poznańskie Studia Slawistyczne” 16/2019, nr 16, s. 144. („Temat II wojny światowej znajdował się w centrum zaciekłych debat, odkąd Chorwacja uzyskała niepodległość na początku lat dziewięćdziesiątych. Korzeni tych debat politycznych i konfliktów ideologicznych należy szukać nie tylko w wydarzeniach z II wojny światowej, ale także w interpretacjach tych wydarzeń po 1945 r. i po 1990 r.”, thum. M. Dyras). 
Takie decyzje rządu i oczekiwania związane z działaniem Rady związane są z intensyfikacją dyskursu memorialnego po 1990 roku i odzyskiwaniem thumionej pamięci po upadku reżimów totalitarnych, ale również z niejednoznaczną oceną udziału Chorwatów w II wojnie światowej. Pokazują także, że „współczesna kultura i tożsamość zbiorowa nie są homogeniczne, nie mówią jednym głosem i nie posiadają jednej pamięci"’.

Najlepiej, jak sądzę, pomoże wyjaśnić znaczenie i zawiłości badań nad pamięcią związanych z II wojną światową, koncepcja „węzłów europejskiej pamięci” sformułowana przez Zdzisława Najdera. Powstała ona jako swoista korekta „miejsc pamięci" (lieux de memoire) Pierre'a Nory pozwalająca precyzyjnie uchwycić złożoność fenomenu pamięci zbiorowej. „Zamiast wieloznacznych «miejsc» proponuję używać terminu «węzły pamięci»", pisze Najder.

„Jest bardziej oczywiście metaforyczny, a zarazem semantycznie konkretniejszy. Odnosi się do takich nazw, imion lub dat, które wiążą ze sobą ciągi skojarzeń i odniesień historycznych łączące się w całe zespoły przedmiotów pamiętania i wspominania. Można sobie te zespoły wyobrażać graficznie jako sieci; to jest także najzręczniejsza dla nich nazwa"”.

Autor ilustruje swoje propozycje terminologiczne przykładami; otóż te same miejsca na mapie mogą należeć do różnych sieci wspomnieniowych i przywoływać różne konotacje, jak choćby Breslau, Wrocław, Vratislav czy Królewiec, Koningsberg i Kaliningrad ${ }^{4}$.

Podobnie rzecz się ma z pamięcią o II wojnie światowej w Chorwacji, istnieje bowiem kilka sieci skojarzeń i odniesień historycznych budujących pamięć o wydarzeniach wojennych i powojennych. Przedmiotem swoich rozważań chciałabym uczynić „węzły pamięci” mniejszości o korzeniach niemieckich ${ }^{5}$ zamieszkujących regiony Slawonii, Bačkę, Banat, Baranję) od wieku XVIII, po zawarciu pokoju karłowickiego w 1699 roku i opuszczeniu tych terenów przez Turków.

Osadnicy niemieccy przybywali ze swej ojczyzny w poszukiwaniu chleba, w czasach kryzysu i głodu, ryzykując niekiedy własnym życiem podczas długiej i nie-

${ }^{2}$ E. Rybicka, Miejsce, pamięć, literatura (w perspektywie geopoetyki), „Teksty Drugie”1/2 $(109 / 110) / 2008$, s. 31.

${ }^{3}$ Z. Najder, Węzty europejskiej pamięci, [w:] https://bon.edu.pl/media/book/pdf/Wezly_europejskiej_pamieci-ZN.pdf [dostęp: 05.11.2019].

${ }^{4}$ Ibidem.

${ }^{5}$ Nawiązuję tutaj do ustaleń ze swoich wcześniejszych tekstów poświęconych losowi Szwabów, zob. M. Dyras, Rekonstrukcje tożsamości ,naddunajskich Szwabów” wobec wielojęzyczności kulturowej, [w:] Konstrukcje i dekonstrukcje tożsamości, t. II. Tożsamość wobec wielojęzyczności, red. E. Golachowska, A. Zielińska, Warszawa, Slawistyczny Ośrodek Wydawniczy, 2012, ss. 167-177. 
bezpiecznej podróży. Żyzne ziemie, sprzyjający uprawom rolniczym łagodny klimat wynagradzały trudy podróży i zapewniały ich rodzinom upragniony dobrobyt, zaś wieści o tym przyciagały kolejnych osadników. W XIX wieku dotarła na te tereny następna fala ludności niemieckiej, która do tej pory zamieszkiwała na ziemiach węgierskich.

Mniejszość niemiecka (określana mianem Szwabów-Volksdeutscherów) przez dziesiątki lat wrastała w lokalne środowisko, bezkonfliktowo gospodarowała obok słowiańskich sąsiadów, zachowując swoje obyczaje i język. Zarówno historycy, jak i autorzy tekstów literackich podkreślają znaczącą różnicę w mentalności obu grup. Znamienny jest choćby komentarz autorów opracowania Što se dogodilo s Folksdojčerima? Vladimira Geigera i Ivana Jurkovicia, którzy pod fotografią przedstawiająca grupę ludzi pracujących przy żniwach zamieszczają podpis:

„Rašireno je miśljenje južnoslavenskih naroda o Nijemcima kao izrazito radišnom, točnom i učinkovitome narodu. U usporedbi sa slavenskim pučanstvom smatrani su gospodarskim čudotvorcima, posebice u poljodjelstvu"'.

Dane statystyczne przytaczane przez autorów opracowania ilustrują duży potencjał ekonomiczny gospodarstw Volksdeutscherów oraz firm, które prowadzili. Stosunkowo niewielka była wśród tej zbiorowości liczba inteligencji, bo zaledwie $2 \%{ }^{7}$, natomiast popularne były rzemiosła, młynarstwo, elektrotechnika, przemysł papierniczy i tekstylny, produkcja wina i piwa.

Z wydarzeniami II wojny światowej łączy się szczególnie trudna historia tej mniejszości, której członkowie zwłaszcza w latach wojny skazani byli na dramatyczne wybory. Ze względu na swoje korzenie traktowani byli jako obywatele posiadający zobowiązania wobec Niemiec, a co za tym idzie wcielano ich do formacji militarnych i paramilitarnych, z których potem wielu z nich dezerterowało. W powieściach, o których tu będzie mowa, niejednokrotnie wspominany jest oddział Prinz Eugen oraz oddziały Waffen SS, w których przyszło walczyć powołanym do nich Szwabom. Historycy Vladimir Geiger i Ivan Jurković twierdza, że wersja wydarzeń z lat wojny, przedstawiona przez historyków jugosłowiańskich, jest niezgodna z prawdą: „Uobičajena je pojava da Folksdojčeri bježe iz vojnih jedinica, odbijaju odlazak na Istočni front i izbjegavaju uključivanje u borbu protiv lokalnih partizan-

${ }^{6}$ V. Geiger, I. Jurković, Što se dogodilo s Folksdojčerima? Sudbina Nijemaca u bivšoj Jugoslaviji, Zagreb, Njemačka narodnosna zajednica, Volksdeutsche Gemainschaft, 1993, s. 54. („Powszechna jest opinia narodów południowosłowiańskich o Niemcach jako bardzo pracowitych, punktualnych i skutecznie działających ludziach. W porównaniu ze słowiańskimi sąsiadami uważani są wręcz za cudotwórców", tłum. M. Dyras ).

${ }^{7}$ Ibidem, s. 43. 


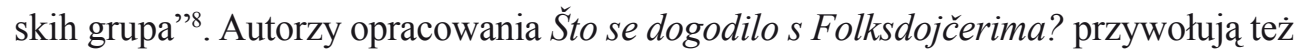
przykład oddziału partyzanckiego Ernst Thälmann sformowanego przez Folksdojčerów 15 sierpnia 1943 roku.

Po wojnie doszło jednak do brutalnej rozprawy z tymi Szwabami, którzy pozostali w Jugosławii i niezależnie od tego, jaką postawę prezentowali w czasie wojny, nowe władze odbierały im majątki, domy, dach nad głową. Większość z nich ${ }^{9}$ władze jugosłowiańskie kierowały do obozów koncentracyjnych (Valpovo, Krndija), gdzie ze względu na trudne warunki bytowe i złe traktowanie czekała ich śmierć. Rodzicom odbierano dzieci, które trafiały na wychowanie do domów słowiańskich sąsiadów. Nikt nie ośmielał się mówić po niemiecku, a niektóre rodziny w obawie o swą przyszłość, zmieniały nazwiska na takie, które brzmiały jak słowiańskie.

Historia tych wydarzeń, aż do lat 90 . XX wieku była starannie ukrywana ${ }^{10}$. Można wręcz mówić o konfiskacie pamięci czy „wymazaniu represyjnym” (Connerton). Dopiero po rozpadzie Jugosławii pojawiają się próby przywołania pamięci o Volksdeutscherach, zaś ich potomkowie, uwolnieni z przymusu milczenia, tworzą opowieści o latach wojny i powojennych represjach władz komunistycznych, budując swą tożsamość wyrastającą z indywidualnej traumy. Wiele z nich przybierze formę narracji literackich motywowanych pamięcią pokaleczoną.

Swoje rozważania usytuuję w kontekście badań nad pamięcią, chciałabym zatem doprecyzować tę kategorię i wskazać na złożony charakter zjawiska, odwołując się do ustaleń teoretycznych Elżbiety Rybickiej. Badaczka postrzega pamięć jako „Zarówno motywację i budulec architektoniki rzeczywistości przedstawionej (czyli koncept literaturoznawczy), jak i kategorię egzystencjalną warunkującą tożsamość indywidualną oraz bycie w świecie (więc pojęcie ze słownika antropologicznego), a wreszcie medium przeszłości i nośnik pamięci zbiorowej (w perspektywie socjokulturowej)"11.

${ }^{8}$ Ibidem, ss. 48-49. („Powszechnym zjawiskiem są ucieczki Volksdeutscherów z jednostek wojskowych, odmawiają oni wyjazdu na front wschodni i unikają walki z lokalnymi grupami partyzantów", thum. M. Dyras ).

${ }^{9}$ Pod koniec 1944 roku ewakuowano tych cywilów, którzy zdecydowali się na wyjazd do Niemiec. Wielu spośród Szwabów nie chciało opuszczać swych domów, ponieważ oczekiwali, że nie będą ukarani za przewinienia innych osób zaangażowanych w czasie wojny po stronie niemieckiej.

${ }^{10}$ Zob. E. Szperlik, Chorwacka (nie)pamięć o Jugostawii. Przemilczenia, pominięcia i odpamiętanie w prozie chorwackiej po roku 1991, Poznań, Wydawnictwo Naukowe UAM, 2019.

${ }^{11}$ Dodajmy jeszcze za badaczką: „Koniunktura memorialna zaznaczyła się bowiem równolegle w różnych dziedzinach - w karierze form autobiograficznych i literatury świadectwa, w rozwoju nowego muzealnictwa i dyskusjach nad nową formułą archiwistyki, debatach nad polityką historyczną i polityką pamięci, w stylach życia coraz bardziej naznaczonych modą retro i oldschoolem a także, oczywiście, w teorii i badaniach literackich oraz historycznych”, E. Rybicka, Miejsce, pamięć, literatura..., op.cit., ss. 20, 27. 
Teksty literackie (literatura funkcjonuje w tym przypadku jako medium pamięci ${ }^{12}$ ), nawiązujące do wydarzeń wojennych i losów Szwabów w państwie jugosłowiańskim, pojawiły się na początku lat 90 . Zestawienie wskazujące obecność tej tematyki w literaturze chorwackiej i serbskiej zatytułowane Sudbina jugoslavenskih Nijemaca u hrvatskoj i srpskoj književnosti (2009) przygotował Vladimir Geiger. Warto też wspomnieć o tekście Lidiji Dujić pod znaczącym tytułem Podunavski Nijemac - statist i(li) suputnik suvremene hrvatske proze (Naddunajski Niemiec - statysta czy współtowarzysz współczesnej prozy chorwackiej), w którym autorka konstatuje, że współczesna proza chorwacka potrzebuje dialogu z Innym i wskazuje na różne role, jakie odgrywają w niej postaci Folksdojčerów ${ }^{13}$ (na przykładzie prozy Ivana Aralicy, Dubravki Ugrešić i Josipa Palady).

Pierwszą w tym nurcie była powieść ${ }^{14}$ Ludwiga Bauera Krótka kronika rodziny Weberów (Kratka kronika porodice Weber, 1990), która ukazała się w Sarajewie w wydawnictwie „Svijetlost”, ze względu na odmowę wydawnictw chorwackich postrzegających książkę jako antysystemową.

Krótka kronikę... z punktu widzenia genologii określić można mianem powieści rodzinnej, zaś rodzina, o której mowa, reprezentuje tutaj całą mniejszość niemiec$\mathrm{ka}^{15}$. Narrator odtwarza historię rodziny Weberów na podstawie listów, zapisków, fotografii i prywatnych dokumentów oraz kroniki rodzinnej skreślonej ręką Gizeli, jednej spośród najmłodszych potomków rodu. Dzieje rodziny śledzimy począwszy od przybycia na ziemie chorwackie w połowie XIX wieku, przodka rodziny Vilmosa, wygnanego z Wegier po burzliwych wydarzeniach 1848 roku na głuchą chorwacką prowincję, gdzie osiadł w miasteczku Gradec (miejscu fikcyjnym, stworzonym przez pisarza na potrzeby swych opowieści). Rekonstrukcja historii rodziny obejmuje okres aż do lat powojennych XX wieku i pozwala prześledzić losy potomków Vilmosa, ich edukację, studia za granica, udział w życiu Gradeca, zaangażowanie w przemiany cywilizacyjne regionu. Często wspominane są wysiłki modernizacyjne Weberów, zmierzające do budowy domów według nowoczesnych projektów (tzw. weberice), budowy mostu oraz wyjątkowa przedsiębiorczość członków rodziny (między innymi prowadzenie tartaku). Takie działania wpisują się w stereotyp pracowitego Niemca, którego wysiłki stają się źródłem postępu, a zarazem wzorem dla słowiańskich sąsiadów ${ }^{16}$. Członkowie rodziny podczas wojny znajdują się po wła-

${ }^{12}$ A. Erll, Literatura jako medium pamięci zbiorowej, [w:] Pamięć zbiorowa i kulturowa. Wspótczesna perspektywa niemiecka, red. M. Saryusz-Wolska, Kraków, Universitas, 2009, ss. 211-247.

${ }^{13}$ Zob. L. Dujić, Podunavski Nijemac - statist i(li) suputnik suvremene hrvatske proze, „Godišnjak Njemačke narodnosne zajednice”, 2005, ss. 211-216.

${ }^{14}$ Pierwszym tekstem dramatycznym poświęconym tej tematyce był Heimat Kaći Ćelan.

${ }^{15}$ Zob. D. Durić, Između književnosti i pamćenja: prisjećanje zaboravljenoga, Rijeka, Filozofski fakultet Sveučilišta u Rijeci 2018, s. 125.

${ }^{16}$ Taki obraz działań Szwabów znajduje potwierdzenie w faktach historycznych. 
ściwej stronie, jeden z nich otwarcie współpracuje z partyzantami, pozostali trzeźwo oceniają sytuację i sprzeciwiają się działaniom władz niemieckich. Krótka kronika... znalazła kontynuację w kilku powieściach Ludwiga Bauera. Kolejne książki, jak opublikowane już wiele lat później Miejsce rodzinne, zapomnienie (Zavičaj zaborav, 2010) oraz Wieża kwaśnych jabłek (Toranj kiselih jabuka, 2013) tworzą swego rodzaju cykl, a ostatnia $\mathrm{z}$ wymienionych powieści, o charakterze autobiograficznym, przynosi wiele informacji o doświadczeniach życiowych autora i pozwala na nowo odczytać sensy pojawiające się we wcześniejszych tekstach.

Autorką, która porusza tematykę obecności Szwabów w społeczności Osijeku, miasta wielokulturowego i wielojęzycznego, jest Ivana Šojat-Kuči, która napisała powieść Unterstadt (2009). Tytułowe miejsce to dzielnica miasta, w której wychowała się protagonistka Katarina, odkrywająca prawdziwą przeszłość swojej „szwabskiej” rodziny dopiero po śmierci matki, z którą nigdy nie mogła znaleźć wspólnego języka. Bohaterce udaje się odtworzyć losy czterech pokoleń swoich przodków, przede wszystkim jednak historie kobiet, dzięki którym ta rodzina przetrwała. Opowieści Frau Jozefiny, przyjaciółki i powierniczki babci Katariny, „mowa” przedmiotów wypełniających dom, a także fotografie znalezione w pokoju babci, pozwalają tropić ślady skrywanych przez lata tajemnic. Matka, Marija, osoba chłodna, wycofana, obsesyjnie dbająca o porządek, przeżyła szereg lat obciążona traumą znaną wszystkim potomkom rodzin o niemieckich korzeniach. Wśród jej członków były osoby zaangażowane po stronie hitlerowskich Niemiec, były też postaci związane z ruchem partyzanckim i ludzie obojętni, pozostający na uboczu wydarzeń wojennych. Wszyscy ci, którzy przeżyli, zostali przez nowe władze jugosłowiańskie skazani na egzystencję wypełnioną strachem i poniżeniem. Dla matki Katariny oraz Frau Jozefiny pobyt w obozie oznaczał śmierć ich najmłodszych dzieci, po której nigdy się nie otrząsnęły. W życiu tych kobiet szczególne miejsce zajęły przemilczenia, skrywanie prawdziwych uczuć, usiłowanie przetrwania za wszelką cenę. W przypadku Katariny można wręcz mówić o szoku, którego doświadcza, kiedy poznaje prawdę o swoim pochodzeniu oraz historię rodziny ${ }^{17}$. Ważnym zabiegiem jest tu ukazanie dwóch perspektyw, świadka wydarzeń (Jozefiny) oraz Katariny, której odkrywanie prawdy o przeszłości zależy od impulsów, jakie dostarczy opowieść Jozefiny. Dejan Durić, analizując tę powieść, zauważa, że wprowadzenie wielu perspektyw narracyjnych (słyszymy także głos wszechwiedzącego narratora), umożliwia pojawienie się i przenikanie różnych typów pamięci, daje wgląd w przeszłość na poziomie indywidualnym i zbiorowym. Pamięć rodzinna, etniczna (mniejszości niemieckiej) i nowa

${ }^{17}$ L. Bauer, Unterstadt - ženska strana donaušvapske povijesti, [w:] Zbornik radova 18. znanstvenog skupa ,, Nijemci i Austrijanci u hrvatskom kulturnom krugu”, red. L. Bauer, Osijek, Njemačka zajednica-Zemaljska udruga Podunavskih Švaba u Hrvatskoj, 2011, s. 165. 
pamięć kolektywna narzucona przez władze powojennej socjalistycznej Jugosławii, różnią się od siebie. Dzięki takiej konfrontacji możemy dostrzec i zrozumieć skomplikowane działanie mechanizmów pamięci ${ }^{18}$.

Jeszcze inną powieścią, czerpiącą z pamięci prywatnej i ściśle związaną z historią rodziny jest Epoka brazu (Doba mjedi, 2015) Slobodana Šnajdera, powieść nagradzana i chwalona w Chorwacji (z pewnymi nielicznymi wyjątkami), którą pisarz poświęcił rodzicom, przede wszystkim jednak zainspirowana losem ojca ${ }^{19}$. Krytycy, nie bez racji, chcą postrzegać Epokę brązu jako próbę odnalezienia tożsamości w ciężkich czasach oraz poszukiwanie prawdy o sprawach bolesnych i przemilczanych.

Doba mjedi składa się z trzech części obejmujących różne miejsca i czasy. Pierwsza Transilvanija rozpoczyna się w roku 1769, kiedy z ziem niemieckich, gdzie szerzy się głód i bieda, ludzie wyruszają na specjalnych łodziach, niesionych nurtem Dunaju, w poszukiwaniu lepszego życia. Wśród podróżnych znajduje się praojciec Kempf, antenat rodziny, którego potomkowie rozpoczną życie, nie w mitycznej Transylwanii, jak obiecywano przed wyjazdem, ale w Slawonii.

${ }^{18}$ D. Durić, Između književnosti i pamćenja ..., op.cit. ss. 93-94.

${ }^{19}$ Ważny komentarz dotyczący losów pisarza Đ. Šnajdera w czasie wojny napisał Branimir Donat: "Đuro Šnajder (Nuštar, 1919 - Zagreb, 1993) pripadao je imućnoj folksdojčerskoj obitelji, dakle onom dijelu njemačke narodonosne skupine koja je bila dio korpusa podunavskih Švaba. Kada je započeo Drugi svjetski rat, takvih se osoba sjetila domovina i sve sposobne za vojsku odmah je unovačila u Wehrmacht. Među njima je bio i naš Đuro iz ove priče, koji je do raspada Jugoslavije studirao u Beogradu. Čim se zaratilo, vraća se kući i uskoro u uniformi vojnika Wehrmachta odlazi na Istočno ratište, gdje je uskoro ranjen. Kao ranjenik dolazi u neku bolnicu u Poljskoj, odakle bježi među poljske partizane. Među njima je dočekao kraj rata, iz kojega se vraća u Vinkovce biciklom. U biografijama (odnosno u bilješkama o piscu, u Šnajderovim knjigama), od cijele te odiseje spominje se samo neobjašnjivi boravak među poljskim partizanima. Cijelu priču netko je jamačno morao znati, ali ipak, Šnajder je shvaćao da je okružen vukovima željnim da se i dalje bore s neprijateljima, a takav je mogao biti svatko tko je, bez obzira na razloge i motive, nosio odoru njemačkoga vojnika. Znalo se da je neprijatelj na kraju krajeva samo neprijatelj i zato se Šnajder nikada nije prihvatio neugodna posla ljuštenja luka”, B. Donat, Ljuštenje luka ... na hrvatski način, „Vijenac” $2008 \mathrm{nr} 367$ [w:] https://www.matica.hr/vijenac/367/ ljustenje-luka-na-hrvatski-nacin-4780/ [dostęp: 03.11.2019]. „Đuro Šnajder (Nuštar, 1919 - Zagreb, 1993) należał do zamożnej rodziny Volksdeutscherów, czyli do tej części niemieckiej grupy etnicznej, która wchodziła w skład grupy naddunajskich Szwabów. Kiedy rozpoczęła się II wojna światowa, ojczyzna przypomniała sobie o takich ludziach i natychmiast zwerbowała do Wehrmachtu wszystkich zdolnych do odbycia służby wojskowej. Wśród nich był i nasz Đuro, który studiował w Belgradzie aż do rozpadu Jugosławii. Gdy tylko wybuchła wojna wrócił do domu i wkrótce w mundurze żołnierza Wehrmachtu udał się na front wschodni, gdzie wkrótce został ranny. Trafił potem do szpitala w Polsce, skąd uciekł do partyzantki. Wśród polskich partyzantów powitał koniec wojny, po czym powrócił do Vinkovców na rowerze. W biografiach (czyli w notatkach o pisarzu, w książkach Šnajdera), z całej tej odysei wspomina się jedynie, nie do końca wytłumaczony, pobyt wśród polskich partyzantów. Ktoś na pewno musiał znać całą tę historię, ale Šnajder zdawał sobie sprawę, że otoczony jest przez «wilki» skłonne do dalszej walki z wrogiem, a takim mógł być każdy, kto z jakiegokolwiek powodu nosił mundur żołnierza niemieckiego. Wiadomo było, że wróg jest ostatecznie tylko wrogiem i dlatego Šnajder nigdy nie podjął się niewdzięcznej pracy obierania cebuli”, tłum. M. Dyras. Donat w oczywisty sposób odwołuje się do autobiograficznej prozy Güntera Grassa Przy obieraniu cebuli (2006). 
W kolejnych częściach powieści zatytułowanych Folksdojčer Kempf i Revolucija $u$ doba mjedi, narrator odtwarza losy Georga Kempfa, a właściwie swojego ojca Đura Šnajdera ${ }^{20}$. Folksdojčer Kempf, młodzieniec ceniący sobie życiowe uciechy, miłośnik literatury, rozczytany w poezji Beaudleaire'a zostaje po wybuchu wojny wcielony w szeregi Waffen SS ( jako, ,prisilni dragovoljac”- przymusowy ochotnik) i wysłany po przeszkoleniu do Polski. Mimo iż pełni służbę w formacjach SS relacje narratora wskazująna fakt, że Georg/Đuro Kempf/Šnajder był tzw. „,dobrym Niemcem”, wrażliwym i niegodzącym się na okrucieństwa wojny. Kempf nie chcąc uczestniczyć w egzekucji członków polskiego ruchu oporu symuluje chorobę, zawsze i za wszelką cenę unika zabijania. Zostaje wreszcie ranny i po pobycie w lazarecie podejmuje próbę ucieczki, ponieważ nie chce już wracać do swojego oddziału. Tuła się zatem po Polsce, służy u różnych gospodarzy, bacznie obserwuje zachowania ludzi. Pisarz potwierdza w wywiadach, że napisanie tej powieści poprzedziły liczne lektury i analiza dokumentów historycznych. Wynikiem tak prowadzonych badań stały się sekwencje, które ukazują Polaków wyłącznie w bardzo negatywnym świetle ${ }^{21}$ :

„Ta gospodyni zapoznała go z krótkimi podstawami polskiego ludowego antysemityzmu, jak sam sobie Kempf nazwał jej wywody o Żydach z pobliskiego miasteczka, którzy naraz wszyscy zniknęli22",

„Ta prostolinijna polska chłopka z głębi swej duszy nienawidzi Żydów i sądzi, że wie, z jakiego powodu ${ }^{23 "}$.

Kempf pozostaje obojętny na taką argumentację, bo przecież nigdy nie był antysemita, a kiedy jeszcze uczęszczał do szkoły zawsze bronił swojego kolegi o żydowskim pochodzeniu przed atakami innych uczniów. Bohater powieści podczas wędrówki po polskich ziemiach trafia w końcu do oddziału radzieckiego, co ostatecznie uratuje mu życie. Przebieg wydarzeń jest stale komentowany przez „nienarodzonego", syna Georga Kempfa, który oczekuje z obawą na swoje przyjście na świat i uważnie śledzi losy rodziców. „Nie-narodzony” opowiada także o swojej przyszłej matce, więzionej w obozie Stara Gradiška, kobiecie o lewicowych poglądach,

${ }^{20}$ Zob. M. Czerwiński, Drugi svjetski rat u hrvatskoj i srpskoj prozi (1945-2015), Zagreb, Hrvatska sveučilišna naklada, 2018, s. 270.

${ }^{21}$ Warto w tym miejscu przywołać tekst Sławomira Buryły, Drażliwe tematy z historii polsko-żydowskiej w eseistyce Henryka Grynberga, [w:] Teraźniejszość i pamięć przeszłości. Rozumienie historii w literaturze polskiej XX i XXI wieku, red. H. Gosk i A. Zieniewicz, Warszawa, Dom Wydawniczy Elipsa, 2006, ss. 213-228. Autor wskazuje na całe spektrum postaw okupacyjnych, a także na zbyt idealistyczne postrzeganie czasów wojny w literaturze polskiej. Šnajder natomiast buduje postać Kempfa tendencyjnie, odwołując się jedynie do polskiego antysemityzmu.

${ }^{22}$ S. Šnajder, Doba mjedi, Zagreb, TIM press, 2015, s. 187, cytaty thum. M. Dyras.

${ }^{23}$ Ibidem, s. 188. 
oddanej partii i bardzo aktywnej. Jednak to nie ona jest tu najważniejsza. Wydaje się, że wysiłek narratora ukierunkowany jest na stworzenie stereotypu „dobrego Niemca" i „dobrego ojca”, co można traktować jako rodzaj terapii, ucieczkę w sferę pamięci prywatnej, w przeszłość, w celu odzyskania klucza do własnej tożsamości. Tak też interpretuje strategię Šnajdera Zlatko Kramarić24, który wskazuje, że pisarz, wybielając postać ojca, podtrzymuje liczne stereotypy, w tym „złego Chorwata”.

W przypadku wszystkich przywołanych tu powieści szczególne znaczenie ma praca pamięci, która staje się podstawą tożsamości. Ta tożsamość nie jest jednak dana, trzeba ją wywalczyć, wynegocjować, wyszarpnąć. Pierre Nora zauważył, że dokonała się ostatnio dekolonizacja mniejszościowych pamięci, która „rozkwita na gruzach dwudziestowiecznych reżimów totalitarnych lub komunistycznych bądź nazistowskich, bądź po prostu dyktatorskich: dekolonizacja ideologiczna, sprzyjająca spotkaniu wyzwolonych narodów z ich pamięciami długimi, tradycyjnymi, które owe reżimy konfiskowały, niszczyły lub manipulowały 25 ".

Praktyki twórcze współczesnych pisarzy, a mam tu na myśli nie tylko chorwackich autorów, ujawniają zainteresowanie problematyką pamięci i rekonstrukcji przeszłości, mechanizmami wyparcia i zapomnienia. Polski badacz, autor monografii Formy pamięci, Marek Zaleski wskazuje na ważny kontekst tego fenomenu:

„Nie ulega wątpliwości, że przyczyna tego zjawiska leży w splocie przemian cywilizacyjnych, wydarzeń historycznych i politycznych, a więc zewnętrznych wobec literatury okoliczności, od których jednak abstrahować nie podobna: odmowa pamiętania, a potem rehabilitacja kaleczonej pamięci, błądzenie, gubienie i odnajdywanie utraconego bądź zakwestionowanego wzoru ciągłości, tożsamości jednostkowej i zbiorowości stanowi dla nas dzisiaj doświadczenie kluczowe" ${ }^{" 26}$.

Powieści Ludwiga Bauera, Ivany Šojat-Kuči i Slobodana Šnajdera są odpowiedzią na odmowę pamiętania, stanowią wyraz dążenia do odzyskania tożsamości poprzez odwołanie do takiej wizji przeszłości, która jest wolna od ideologicznych ograniczeń. Literatura, w tym przypadku, spełniła znaczącą rolę w procesie kształtowania pamięci i tożsamości oraz wzajemnych ich relacji27. Można wręcz uznać, że dała impuls do zmiany interpretacji zarówno pamięci zbiorowej, jak i indywidualnej w nowej sytuacji polityczno-historycznej.

${ }^{24}$ Zob. Z. Kramarić, Dobar Nijemac, [w:] https://www.matica.hr/vijenac/592/dobar-nijemac26159/ [dostęp: 07.11.2019].

${ }^{25}$ P. Nora, Czas pamięci, thum. W. Dłuski, „Res Publica Nowa” 2001 nr 7, s. 41.

${ }^{26}$ M. Zaleski, Formy pamięci, słowo/obraz terytoria, Gdańsk 2004, ss. 5-6.

${ }^{27}$ Zob. B. Neumann, Literatura, pamięć, tożsamość, [w:] Pamięć zbiorowa i kulturowa..., op.cit., s. 280 . 


\section{Literatura}

Bauer L., Kratka kronika porodice Weber, Zaprešić, Fraktura, 2007, 228 ss.

Buryła S. Drażliwe tematy z historii polsko-żydowskiej w eseistyce Henryka Grynberga, [w:] Teraźniejszość i pamięć przeszłości. Rozumienie historii w literaturze polskiej XX i XXI wieku, red. H. Gosk i A. Zieniewicz, Warszawa, Dom Wydawniczy Elipsa, 2006, ss. 213-228.

Czerwiński M., Drugi svjetski rat u hrvatskoj i srpskoj prozi (1945-2015), Zagreb, Hrvatska sveučilišna naklada, 2018, 301 ss.

Donat B., Ljuštenje luka... na hrvatski način, „Vijenac” 2008 nr 367, [w:] https:// www.matica.hr/vijenac/367/ljustenje-luka-na-hrvatski-nacin-4780/ [dostęp: 03.11.2019].

Dujić L., Podunavski Nijemac - statist i(li) suputnik suvremene hrvatske proze, „Godišnjak Njemačke narodnosne zajednice”, 2005, ss. 211-216.

Durić D., Između književnosti i pamćenja: prisjećanje zaboravljenoga, Rijeka, Filozofski fakultet Sveučilišta u Rijeci, 2018, 256 ss.

Dyras M., Rekonstrukcje tożsamości „,naddunajskich Szwabów” wobec wielojęzyczności kulturowej, [w:] Konstrukcje i dekonstrukcje tożsamości, t. II. Tożsamość wobec wielojęzyczności, red. E. Golachowska, A. Zielińska, Warszawa, Slawistyczny Ośrodek Wydawniczy, 2012, ss. 167-177.

Erll A., Literatura jako medium pamięci zbiorowej, [w:] Pamięć zbiorowa i kulturowa. Współczesna perspektywa niemiecka, red. M. Saryusz-Wolska, Kraków, Universitas, 2009, ss. 211-247.

Geiger V., Jurković I., Što se dogodilo s Folksdojčerima? Sudbina Nijemaca u bivšoj Jugoslaviji, Zagreb, Njemačka narodnosna zajednica, Volksdeutsche Gemainschaft, 1993, 140 ss.

Koren S., Dialogue Document Without Dialogue: Current Debates on World War II in Croatia, „Poznańskie Studia Slawistyczne” 2019, nr 16, ss. 143-157.

Kramarić Z., Dobar Nijemac, [w:] https://www.matica.hr/vijenac/592/dobar-nijemac-26159/ [dostęp: 07.11.2019].

Najder Z., Węzly europejskiej pamięci, [w:] https://bon.edu.p1/media/book/pdf/ Wezly_europejskiej_pamieci-ZN.pdf [dostęp: 05.11.2019].

Neumann B., Literatura, pamięć, tożsamość [w:] Pamięć zbiorowa i kulturowa. Współczesna perspektywa niemiecka, red. M. Saryusz-Wolska, Kraków, Universitas, 2009, ss. 249-284.

Nora P., Czas pamięci, thum. W. Dłuski, „Res Publica Nowa” 2001, nr 7, ss. 37-44. Rybicka E., Miejsce, pamięć, literatura (w perspektywie geopoetyki), „Teksty Drugie” 2008, nr 1/2 (109/110), ss. 19-32. 
Szperlik E., Chorwacka (nie)pamięć o Jugostawii. Przemilczenia, pominięcia i odpamiętanie w prozie chorwackiej po roku 1991, Poznań, Wydawnictwo Naukowe UAM, 2019, 302 ss.

Šnajder S., Doba mjedi, Zagreb, TIM press, 2015, 372 ss.

Šojat-Kuči I., Unterstadt, Zaprešić, Fraktura, 2009, 427 ss.

Zaleski M., Formy pamięci, Gdańsk, słowo/obraz terytoria, 2004, 341 ss.

\section{References}

Bauer L., Kratka kronika porodice Weber [A Brief Chronicle of the Weber Family], Zaprešić, Fraktura, 2007, 228 pp.

Buryła S. Drażliwe tematy z historii polsko-żydowskiej w eseistyce Henryka Grynberga [SensitiveTopics of Polish-Jewish History in Henryk Grynberg's Essays], [in:] Teraźniejszość i pamięć przeszłości. Rozumienie historii $w$ literaturze polskiej XX i XXI wieku [The Present and Memory of the Past. Understanding History as Depicted in Polish Literature of the $20^{\text {th }}$ and $21^{\text {st }}$ Centuries], H. Gosk i A. Zieniewicz (Eds.), Warszawa, Dom Wydawniczy Elipsa, 2006, pp. 213-228. Czerwiński M., Drugi svjetski rat u hrvatskoj i srpskoj prozi (1945-2015) [The Second World War in Croatian and Serbian Prose Narrative (1945-2015)], Zagreb, Hrvatska sveučilišna naklada, 2018, 301 pp.

Donat B., Ljuštenje luka... na hrvatski način [Peeling Onions... in the Croatian Way], "Vijenac" 2008, no. 367. Available at: https://www.matica.hr/vijenac/367/ljustenje-luka-na-hrvatski-nacin-4780/ [accessed: 03.11.2019].

Dujić L., Podunavski Nijemac - statist i(li) suputnik suvremene hrvatske proze [Danubian German - Extra and (or) Companion of Contemporary Croatian Prose], "Godišnjak Njemačke narodnosne zajednice", 2005, pp. 211-216.

Durić D., Između književnosti i pamćenja: prisjećanje zaboravljenoga [Between Literature and Memory: Remembering the Forgotten], Rijeka, Filozofski fakultet Sveučilišta u Rijeci, 2018, 256 pp.

Dyras M., Rekonstrukcje tożsamości ,naddunajskich Szwabów” wobec wielojęzyczności kulturowej [Reconstructions of the "Donauschwabe" Identity in the Face of Cultural Multilingualism], [in:] Konstrukcje i dekonstrukcje tożsamości [Constructions and Deconstructions of Identity], vol. II. Tożsamość wobec wielojęzyczności [Identity in the Face of Multilingualism], E. Golachowska, A. Zielińska (Eds.), Warszawa, Slawistyczny Ośrodek Wydawniczy, 2012, pp. 167177.

Erll A., Literatura jako medium pamięci zbiorowej [Literature as a Medium of Collective Memory], [in:] Pamięć zbiorowa i kulturowa. Wspótczesna perspektywa 
niemiecka [Collective and Cultural Memory. Contemporary German Perspective], M. Saryusz-Wolska (Ed.), Kraków, Universitas, 2009, pp. 211-247.

Geiger V., Jurković I., Što se dogodilo s Folksdojčerima? Sudbina Nijemaca u bivšoj Jugoslaviji [What happened to the Volksdeutscher? The fate of the Germans in the former Yugoslavia], Zagreb, Njemačka narodnosna zajednica, Volksdeutsche Gemainschaft, 1993, 140 pp.

Koren S., Dialogue Document Without Dialogue: Current Debates on World War II in Croatia, „Poznańskie Studia Slawistyczne” [Poznań Slavic Studies] 2019, no. 16 , pp. 143-157.

Kramarić Z., Dobar Nijemac [Good German]. Available at: https://www.matica.hr/ vijenac/592/dobar-nijemac-26159/ [accessed: 07.11.2019].

Najder Z., Węzły europejskiej pamięci [Knots of European Memory]. Available at: https://bon.edu.pl/media/book/pdf/Wezly_europejskiej_pamieci-ZN.pdf [accessed: 05.11.2019].

Neumann B., Literatura, pamięć, tożsamość [Literature, Memory, Identity], [in:] Pamięć zbiorowa i kulturowa. Wspótczesna perspektywa niemiecka, Pamięć zbiorowa i kulturowa. Wspótczesna perspektywa niemiecka [Collective and Cultural Memory. Contemporary German Perspective], M. Saryusz-Wolska (Ed.), Kraków, Universitas, 2009, pp. 249-284.

Nora P., Czas pamięci [The Time of Memory], trans. W. Dłuski, "Res Publica Nowa" 2001, no. 7, pp. 37- 44.

Rybicka E., Miejsce, pamięć, literatura (w perspektywie geopoetyki), [Venue, Memory, Literature (in the Perspective of Geo-Poetics)], "Teksty Drugie” 2008, no. 1/2 (109/110), pp. 19-32

Szperlik E., Chorwacka (nie)pamięć o Jugosławii. Przemilczenia, pominięcia i odpamiętanie w prozie chorwackiej po roku 1991 [Croatian (dis)Memory of Yugoslavia. Concealments, Omissions and (Re)membrance in Croatian Prose after 1991], Poznań, Wydawnictwo Naukowe UAM, 2019, 302 pp.

Šnajder S., Doba mjedi [The Age of Bronze], Zagreb, TIM press, 2015, 372 pp.

Šojat-Kuči I., Unterstadt, Zaprešić, Fraktura, 2009, 427 pp.

Zaleski M., Formy pamięci [Forms of Memory], Gdańsk, słowo/obraz terytoria, 2004, $341 \mathrm{pp}$. 
